\title{
Studi Eksplorasi Desain Rumah Prafabrikasi Berdasarkan Bentuk Modul Komponen sebagai Alternatif Desain Rumah Sederhana
}

\author{
Anjar Primasetra ${ }^{1}$ \\ Arsitektur, Fakultas Teknik dan Desain, Institut Teknologi Sains Bandung, Cikarang, Indonesia \\ Email:anjar.primasetra@itsb.ac.id
}

Informasi naskah:

Diterima

10 Desember 2019

Direvisi

11 Januari 2020

Disetujui terbit

14 Februari 2020

Diterbitkan

28 Februari 2020

\begin{abstract}
The needs for rapid housing construction has become a very important issue nowadays because of very high housing backlog. Housing construction in the community still use conventional construction systems that have many weaknesses, one of it weakness is the problem of delays in construction time that often occurs due to project managerial problems and poor HR capacity. One alternative for accelerating development is the usage of prefabrication method. Prefabrication method allows the creation of a system to speed up the house building construction is commonly called a prefabricated house. The prefabrication industry in Indonesia is less rapidly developing because its components tend to have rigid designs that make it unattractive, and the costs are relatively more expensive when compared to conventional house. There are four types that includes in prefabricated houses that have been known before, they are RISHA, RUMANAGA, DOMUS, and DUBLDOM. The four prefabricated houses have been assessed in terms of building components and design through industrial research and development. This research is aimed to conduct a study of exploration of prefabricated house design by evaluating the weaknesses of prefabricated houses, especially in terms of module shape and components. In addition, it also examines the minimum size of house area needed in fulfilling the size of a modest house according to a literature study from previous research. From the evaluation results, the prefabricated house design is then formulated in several design alternatives to look for the possibility designs that can be developed. From the results of the study, the size of the module developed to explore the design is to use modules with multiples of $30 \mathrm{~cm}$ with a minimum size of the module is $2.4 \mathrm{~m} \mathrm{x} 2.4 \mathrm{~m}$ and the maximum size of the module is $3 \mathrm{~m} \mathrm{x} 3 \mathrm{~m}$. Meanwhile, for the area of the house building that was developed there were three alternatives area of the house chosen, they are: small type $\left(28.8 \mathrm{~m}^{2}\right)$, medium type $\left(36 \mathrm{~m}^{2}\right)$, large type $\left(43.2 \mathrm{~m}^{2}\right)$ with minimal house needs, they are: gathering space (living room/room family/kitchen), bedroom, service room (bathroom), and terrace. It is expected that the results of design exploration will be an alternative design for the development of simple home designs.
\end{abstract}

Keywords: exploration, design and planning, house, modular, prefabrication 


\section{PENDAHULUAN}

Kebutuhan pembangunan rumah yang cepat telah menjadi sangat penting dewasa ini dikarenakan terjadi backlog perumahan yang sangat tinggi. Kemenpera mengeluarkan data pada tahun 2010 yang berbunyi bahwa 8,2 juta rumah belum terpenuhi di masyarakat. Menurut Bappenas, sembilan juta rumah belum terpenuhi. Dari hasil sensus penduduk tahun 2010, backlog menemui angka yang besar yakni sekitar 13,6 juta rumah belum terpenuhi di masyarakat ${ }^{1)}$.

Pemenuhan rumah yang lambat juga disebabkan oleh faktor proses konstruksi. Pembangunan rumah di masyarakat masih menggunakan sistem konstruksi konvensional yang memiliki banyak kelemahan, salah satunya adalah masalah keterlambatan waktu pembangunan yang sering terjadi karena permasalahan manajerial proyek dan kapasitas SDM yang tidak baik. Salah satu alternatif bagi percepatan pembangunan adalah dengan menggunakan metode industrialisasi konstruksi dengan cara metode prafabrikasi. Metode prafabrikasi memungkinkan terciptanya sistem rumah cepat bangun atau biasa disebut dengan rumah prafabrikasi.

Industri prafabrikasi di Indonesia kurang berkembang pesat dikarenakan komponennya cenderung memiliki desain yang kaku yang menjadikannya tidak menarik, dan biaya yang relatif lebih mahal jika dibandingkan dengan rumah konvensional. Ada empat rumah prafabrikasi yang telah dikenal dan dipelajari oleh peneliti sebelumnya yaitu RISHA, RUMANAGA, DOMUS, dan DUBLDOM. Keempat rumah prafabrikasi tersebut telah dikaji secara komponen bangunan dan desain melalui penelitian dan pengembangan industri. Penelitian ini ditujukan untuk melakukan studi tentang eksplorasi perancangan rumah prafabrikasi dengan cara mengevaluasi kelemahan rumah prafabrikasi yang telah ada di Indonesia khususnya dari aspek desain dalam hal kenyamanan ruang yang tercipta dan program ruang yang terlihat dari layout bangunan rumah. Dari hasil evaluasi tersebut kemudian dirumuskan desain rumah prafabrikasi yang baik secara desain dan dapat diterima oleh masyarakat sehingga rumah prafabrikasi akan menjadi salah satu solusi dari pemenuhan kebutuhan rumah bagi masyarakat.

Batasan penelitian ini adalah rumah prafabrikasi ditinjau secara desain meliputi aspek bentuk dan ukuran modul komponen yang dibuat dalam beberapa alternatif luasan bangunan. Sedangkan, untuk luas bangunan rumah yang dikembangkan terdapat tiga alternatif luas rumah yang dipilih yaitu: tipe kecil $\left(28.8 \mathrm{~m}^{2}\right)$, tipe sedang $\left(36 \mathrm{~m}^{2}\right)$, tipe besar $\left(43.2 \mathrm{~m}^{2}\right)$ dengan kebutuhan rumah minimal yaitu: ruang berkumpul (ruang tamu/ruang keluarga/dapur), ruang tidur, ruang servis (kamar mandi), dan teras.

\subsection{Sistem Modular dalam Konstruksi Prafabrikasi}

Dalam metode prafabrikasi, dikenal beberapa teknis konstruksi yang fundamental, salah satunya adalah dengan konstruksi modular. Berdasarkan Smith (2010), sistem modular berada pada posisi prafabrikasi yang dilihat berdasarkan grid-nya ${ }^{2)}$. Sistem modular pada prinsipnya adalah sistem konstruksi yang bekerja dengan modul-modul atau komponen 
dan bagian dari sistem yang terstandarisasi dengan dimensi dan bentuk yang sama dan presisi sebagai komponen bangunan ataupun sebagian bangunan.

Dalam perancangannya, sebagaimana dalam Amalia (2008), standar SNI untuk modular dalam prafabrikasi telah ditentukan ${ }^{3)}$. Persyaratan teknis yang menjadi dasar Koordinasi Moduler (Dasar Koordinasi Moduler Untuk Perancangan), dalam SK SNI 03-1963-1990 adalah:

1. Ukuran arah horisontal dan vertikal bangunan rumah dan gedung harus berdasarkan multi-modul.

2. Ukuran komponen, elemen dan bangunan rumah dan gedung, mengikuti ketentuan dalam standar mengenai koordinasi moduler.

3. Ukuran - ukuran berguna dari setiap produk komponen dan elemen bangunan non struktural harus memungkinkan penggantian komponen atau elemen bangunan dengan jenis lain.

4. Jarak antar elemen bangunan struktural atau komponen bangunan struktural harus moduler, dapat dipilih sumbu ke sumbu atau jarak bersihnya. Dalam arah vertikal dapat dipilih tinggi tingkat atau tinggi ruangan yang modular.

\subsection{Tinjauan Desain Rumah Prafabrikasi yang Pernah Dikembangkan}

Desain rumah prafabrikasi cenderung monoton dikarenakan penggunaan material yang sejenis dan sistem struktur maupun arsitektur yang modular dan berulang. Namun demikian, desain rumah prafabrikasi yang diambil dalam studi preseden memiliki variasi desain yang menarik untuk dikaji dari sisi layout ruangan, komponen prafabrikasi, komposisi bentuk dan desain, dan material yang dianggap mempengaruhi keleluasaan bentuk modul untuk dieksplorasi. Desain rumah prafabrikasi yang dikaji adalah RISHA, Domus, Rumanaga, dan Dubldom. Tabel 1. memberikan penjelasan singkat dari studi preseden tentang desain rumah prafabrikasi yang diambil sebagai rujukan.

\subsection{Tinjauan Kebutuhan Minimal Ruang dalam Rumah Sederhana}

Pedoman Umum Rumah Sederhana Sehat (Keputusan Mentri Kimpraswil Nomor 403/KPTS/M/2002) $)^{6}$ merumuskan ruang-ruang yang perlu disediakan dalam konsep rancangan Rumah Inti Tumbuh (RIT) adalah sebagai berikut:

1. Satu buah ruang tidur yang memenuhi syarat keamanan. Bagian ini merupakan ruang utuh sesuai dengan fungsi utamanya.

2. Satu buah ruang serbaguna merupakan ruang kelengkapan rumah dimana di dalamnya dilakukan interaksi antar keluarga dan dapat melakukan aktivitas-aktivitas lainnya.

3. Satu kamar mandi/kakus/cuci yang merupakan bagian dalam fungsi servis sebuah rumah tinggal yang sangat menentukan keberfungsian rumah tersebut.

4. Kebutuhan luas minimum untuk bangunan sederhana tidak bertingkat juga dihitung dari faktor kebutuhan udara segar tiap penghuni per jam (Neufert, 1996) ${ }^{7)}$. Suryo (2017) pernah menyebutkan bahwa rentang luas minimal rumah sederhana antara 
$32,01 \mathrm{~m}^{2}-36 \mathrm{~m}^{2}{ }^{8}$. Jika dilihat lebih lanjut, berdasarkan kegiatan yang ada di dalam rumah yaitu tidur, berkumpul, makan, memasak, dan lain-lain, kebutuhan udara segar per-orang dewasa per-jam adalah $16-24 \mathrm{~m}^{3}$ \& per-anak-anak per-jam adalah $8-12 \mathrm{~m}^{3}$, dengan pergantian udara dalam ruang sebanyak dua kali per jam dan tinggi plafon rata-rata 2,5 m, maka luas lantai per orang (SNI 03-1733-2004) (9) $^{\text {a }}$ alah sebagaimana ditunjukkan pada Tabel 2.

Tabel 1. Tinjauan singkat rumah prafabrikasi yang telah dikembangkan

\begin{tabular}{|c|c|c|c|c|c|}
\hline No. & $\begin{array}{c}\text { Rumah } \\
\text { Prafabrikasi }\end{array}$ & $\begin{array}{l}\text { Penjelasan } \\
\text { Singkat }\end{array}$ & $\begin{array}{l}\text { Sistem Struktur } \\
\& \text { Material }\end{array}$ & Ukuran Modul & Foto \\
\hline 1 & RISHA $^{4)}$ & $\begin{array}{l}\text { Rumah } \\
\text { prafabrikasi yang } \\
\text { dikembangkan } \\
\text { oleh } \\
\text { Puslitbangkim } \\
\text { PUPR. }\end{array}$ & $\begin{array}{l}\text { Struktur portal } \\
\text { menggunakan } \\
\text { sistem panel } \\
\text { beton. }\end{array}$ & $\begin{array}{l}1.8 \times 1.8 \text { m dan } \\
3 \times 3 \text { m dengan } \\
\text { dua jenis modul } \\
\text { struktur \& modul } \\
\text { penyambung. }\end{array}$ & \\
\hline 2 & Domus & $\begin{array}{l}\text { Rumah } \\
\text { prafabrikasi yang } \\
\text { dikembangkan } \\
\text { oleh Tata } \\
\text { Logam. }\end{array}$ & $\begin{array}{l}\text { Struktur } \\
\text { menggunakan } \\
\text { baja ringan } \\
\text { dengan dinding } \\
\text { pengisi bata } \\
\text { ringan atau } \\
\text { GRC. }\end{array}$ & $\begin{array}{l}\text { Tidak ada modul } \\
\text { standar dan } \\
\text { bersifat open } \\
\text { system. }\end{array}$ & \\
\hline 3 & Rumanaga ${ }^{5)}$ & $\begin{array}{l}\text { Rumah } \\
\text { prafabrikasi hasil } \\
\text { riset } \\
\text { pengembangan } \\
\text { Green Building } \\
\text { Research Center } \\
\text { ITB. }\end{array}$ & $\begin{array}{l}\text { Struktur rangka } \\
\text { kayu dengan } \\
\text { dinding pengisi } \\
\text { panel bambu. }\end{array}$ & $\begin{array}{l}2.4 \times 2.4 \mathrm{~m} \\
\text { dengan ukuran } \\
\text { modul dinding } \\
60 \times 60 \mathrm{~cm}\end{array}$ & \\
\hline 4 & Dubldom $^{10)}$ & $\begin{array}{l}\text { Rumah } \\
\text { prafabrikasi } \\
\text { berasal dari } \\
\text { Rusia. }\end{array}$ & $\begin{array}{l}\text { Struktur rangka } \\
\text { kayu laminasi. } \\
\text { Dinding } \\
\text { pengisi panel } \\
\text { dengan } \\
\text { insulasi. }\end{array}$ & $\begin{array}{l}\text { Modul rumah } \\
\text { utama berukuran } \\
8 \times 9 \mathrm{~m}\end{array}$ & \\
\hline
\end{tabular}

Tabel 2. Kebutuhan luas lantai minimal rumah sederhana

\begin{tabular}{ccc}
\hline Luas Lantai & Luas Minimal & Luas Maksimal \\
\hline Dewasa & $6,4 \mathrm{~m}^{2}$ & $9,6 \mathrm{~m}^{2}$ \\
Anak-anak & $3,2 \mathrm{~m}^{2}$ & $4,8 \mathrm{~m}^{2}$ \\
Luas hunian & $28,28 \mathrm{~m}^{2}$ & $43,2 \mathrm{~m}^{2}$ \\
\hline Luas hunian rata-rata & \multicolumn{2}{c}{$36 \mathrm{~m}^{2}$} \\
\hline Luas hunian per jiwa & $9 \mathrm{~m}^{2}$ (ukuran ruangan $3 \times 3 \mathrm{~m}$ ) \\
\hline
\end{tabular}




\section{METODE}

Metode yang dilakukan adalah metode kualitatif dengan mengkaji rumah prafabrikasi yang telah ada di Indonesia. Diambil empat sampel yang telah dikenal dan diteliti oleh peneliti sebelumnya yaitu RISHA (Rumah Sehat Instan Sederhana), Rumanaga (Rumah prafabrikasi lokal penelitian sebelumnya), Rumah Domus, dan Rumah Dubldom (Rumah prafabrikasi dari Rusia). Kajian diarahkan pad aspek kedinamisan desain secara komponen prefab-nya, dan program ruang (ruang-ruang yang mendasar dalam sebuah rumah tinggal: ruang tidur utama, ruang tidur anak, ruang keluarga, ruang makan, dan lain sebagainya). Rumusan evaluasi tersebut dijadikan landasan untuk melakukan eksplorasi desain rumah prafabrikasi untuk mendapatkan desain yang optimal. Akan dibuat beberapa alternatif desain rumah prafabrikasi meliputi aspek layout rumah, beberapa tipe luas rumah, modul struktur, sistem struktur yang digunakan, dan material strukturnya. Hasil desain kemudian dianalisis dengan menggunakan analisis deskriptif untuk menceritakan kemungkinan bentuk yang ada dan dampak yang dimunculkan akibat bentuk modul yang telah dirancang tersebut. Proses analisis deskriptif menggunakan software tiga dimensi untuk memperlihatkan berbagai macam bentuk dari hasil eksplorasi desain.

\section{PEMBAHASAN DAN DISKUSI}

\subsection{Hasil Analisis Studi Preseden Desain Rumah Prafabrikasi}

Rumah prafabrikasi yang diambil sebagai referensi dianalisis terlebih dahulu untuk melihat desain dari sisi ukuran modul, komponen rakitan, kemungkinan ruang yang dibentuk, dan jenis material yang digunakan. Hasil analisis adalah sebagai berikut:

Tabel 3. Hasil analisis deskriptif studi preseden

\begin{tabular}{|c|c|c|c|c|c|}
\hline \multirow[t]{2}{*}{ No. } & \multirow[t]{2}{*}{ Variabel } & \multicolumn{4}{|c|}{ Rumah Prafabrikasi } \\
\hline & & RISHA & RUMANAGA & DOMUS & Dubldom \\
\hline \multirow[t]{4}{*}{1} & $\begin{array}{l}\text { Material } \\
\text { struktur }\end{array}$ & Panel Beton pracetak & Panel bambu & $\begin{array}{l}\text { Panel GRC \& bata } \\
\text { beton }\end{array}$ & $\begin{array}{l}\text { Kayu lapis } \\
\text { dengan } \\
\text { sambungan plat } \\
\text { besi \& baut }\end{array}$ \\
\hline & $\begin{array}{l}\text { Material } \\
\text { dinding }\end{array}$ & Panel Beton Pracetak & Kayu pre-cut & Panel lantai GRC & Kayu lapis \\
\hline & $\begin{array}{l}\text { Material } \\
\text { lantai }\end{array}$ & Baut & Baut & Baut \& mortar & Kayu lapis \\
\hline & $\begin{array}{l}\text { Material } \\
\text { atap }\end{array}$ & $\begin{array}{l}\text { Atap baja } \\
\text { ringan/kayu/baja }\end{array}$ & Atap kayu & $\begin{array}{l}\text { Atap baja ringan satu } \\
\text { kesatuan dengan } \\
\text { struktur rangka }\end{array}$ & Atap Metal \\
\hline 2 & $\begin{array}{l}\text { Ukuran \& } \\
\text { bentuk } \\
\text { modul }\end{array}$ & $\begin{array}{l}\text { Terbatas pada } \\
\text { ukuran modul } 3 \times 3 \mathrm{~m} \\
\text { dengan bentuk } \\
\text { ruangan persegi atau } \\
\text { persegi panjang }\end{array}$ & $\begin{array}{l}\text { Ukuran modul } \\
\text { terbatas pada } \\
\text { modul } 60 \mathrm{~cm}\end{array}$ & $\begin{array}{l}\text { Ukuran modul bebas } \\
\& \text { terbuka untuk } \\
\text { desain } \text { custom }\end{array}$ & $\begin{array}{l}\text { Ukuran modul } \\
\text { bebas \& terbuka } \\
\text { untuk desain } \\
\text { custom }\end{array}$ \\
\hline 3 & Desain & $\begin{array}{l}\text { Monoton, kurang } \\
\text { menarik, modulnya } \\
\text { terbatas pada ukuran } \\
\text { tertentu saja }\end{array}$ & $\begin{array}{l}\text { Eksploratif, } \\
\text { cenderung ke } \\
\text { arah tradisional } \\
\text { vernakular }\end{array}$ & $\begin{array}{l}\text { Eksploratif \& } \\
\text { mampu } \\
\text { menyesuaikan desain } \\
\text { rumah modern masa } \\
\text { kini }\end{array}$ & Eksploratif \\
\hline
\end{tabular}




\subsection{Hasil Analisis Eksplorasi Desain}

Studi eksplorasi desain rumah prafabrikasi dimulai dari membuat standar aspek desain yang dirumuskan dari hasil kajian tentang rumah prafabrikasi yang telah dilakukan sebelumnya. Adapun aspek desain yang dibuat terangkum dalam tabel di bawah ini:

Tabel 4. Aspek desain acuan untuk eksplorasi desain

\begin{tabular}{cll}
\hline No. & \multicolumn{1}{c}{ Aspek Desain } & \multicolumn{1}{c}{ Penjelasan } \\
\hline 1 & Program ruang & $\begin{array}{l}\text { Ruang berkumpul (ruang tamu/ruang keluarga/dapur), } \\
\text { ruang tidur, ruang servis }(\mathrm{kamar} \text { mandi), dan teras. }\end{array}$ \\
2 & Luas Bangunan & $\begin{array}{l}\text { Dibuat tiga alternatif luas: tipe kecil }\left(28.8 \mathrm{~m}^{2}\right), \text { tipe } \\
\text { sedang }\left(36 \mathrm{~m}^{2}\right) \text {, tipe besar }\left(43.2 \mathrm{~m}^{2}\right) .\end{array}$ \\
3 & Ukuran modul ruangan & $\begin{array}{l}\text { Ukuran modul menggunakan modul dengan kelipatan } \\
30 \mathrm{~cm} \text { dengan ukuran minimal ruangan adalah } 2.4 \mathrm{~m} .\end{array}$ \\
5 & Sruktur Bangunan & $\begin{array}{l}\text { Dibuat beberapa alternatif struktur, yaitu: beton, baja, } \\
\text { baja ringan, dan kayu balok }\end{array}$ \\
\hline
\end{tabular}

Setelah itu kemudian dibuat eksplorasi modul dengan basis ukuran modul kelipatan $30 \mathrm{~cm}$ dengan ukuran minimal $2.4 \mathrm{~m}$. Ukuran modul dengan kelipatan $30 \mathrm{~cm}$ dimaksudkan agar modul struktur dapat diisi dengan berbagai macam material penutup dinding dan lantai yang kebanyakan juga memiliki ukuran dengan kelipatan $30 \mathrm{~cm}$, misalnya dinding GRC dengan ukuran panel 1.2 x $2.4 \mathrm{~m}$. Hasil eksplorasi desain modul dijelaskan pada gambar di bawah ini:

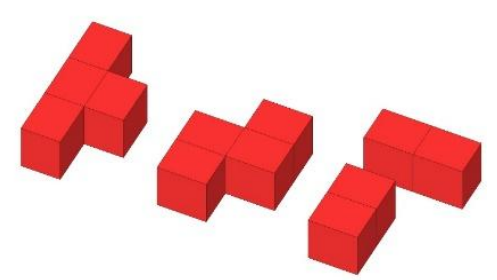

Tipe kecil dengan ukuran modul 2.4 × $3 \mathrm{~m}$ dengan variasi bentuk memanjang, melebar, dan massa terpisah

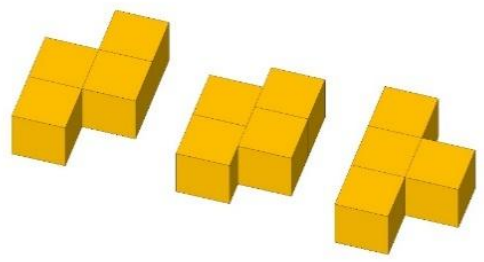

Tipe sedang dengan ukuran modul $3 \times 3 \mathrm{~m}$ dengan variasi bentuk zig-zag, melebar, dan memanjang

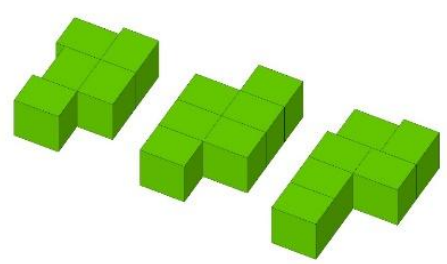

Tipe besar dengan ukuran modul 2.4 x 3 m dengan variasi bentuk melebar, zig-zag, dan memanjang

Gambar 1. Eksplorasi konfigurasi modul rumah 
Gubahan massa dari modul-modul tersebut lalu dibuat ke dalam beberapa alternatif denah rumah tinggal berdasarkan program ruang yang telah disusun berdasarkan studi literatur. Berikut ini adalah hasil denah yang telah dibuat:

Tabel 5. Alternatif denah berdasarkan gubahan massa modul rumah yang telah dibuat

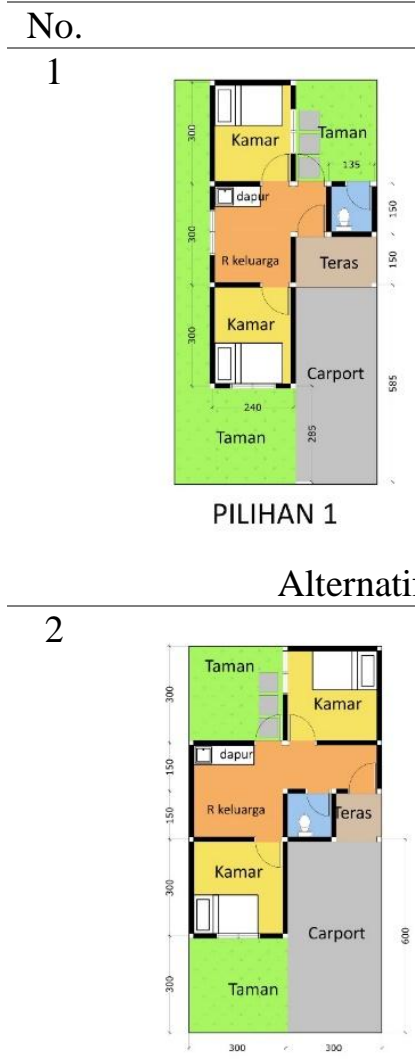

PILIHAN 1 Alternatif Denah

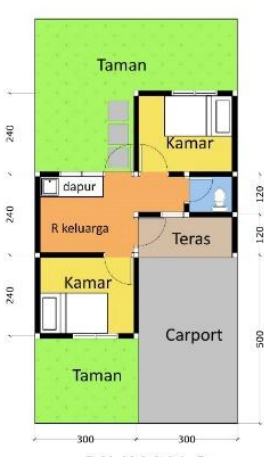

PILIHAN 2

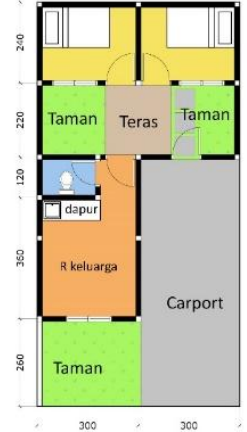

PILIHAN 3

Alternatif tipe sedang dengan luas $36 \mathrm{~m}^{2}$

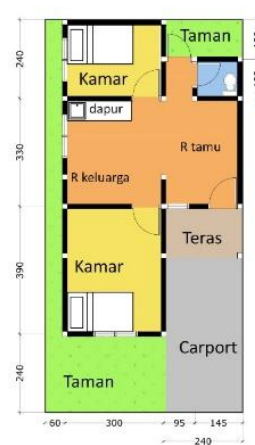

PILIHAN 1

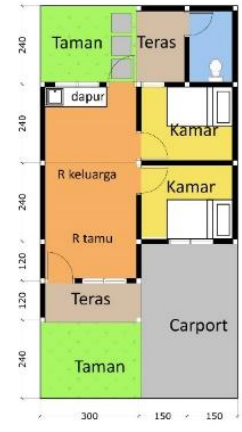

PILIHAN 2

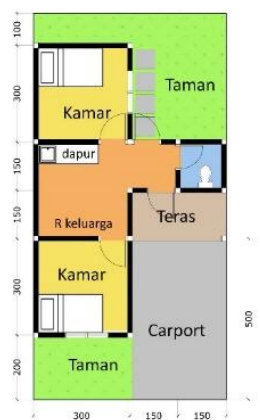

PILIHAN 3

Alternatif tipe besar dengan luas $43.2 \mathrm{~m}^{2}$ 
Dari hasil pembuatan denah, didapat bahwa luas rumah dari masing-masing tipe memiliki ukuran yang sama, namun memiliki konfigurasi massa yang berbeda. Perbedaan ini menimbulkan ukuran luas ruang terbuka hijau yang bervariasi. Berikut ini adalah hasil dari perhitungan luas ruang terbuka hijau/taman (tidak termasuk carport) dengan kasus luas lahan keseluruhan $72 \mathrm{~m}^{2}$ :

Tabel 6. Luas ruang terbuka hijau pada setiap tipe alternatif desain rumah

\begin{tabular}{|c|c|c|}
\hline No. & Tipe & Luas ruang terbuka hijau $\left(\mathrm{m}^{2}\right)$ \\
\hline \multirow[t]{4}{*}{1} & Tipe Kecil (luas rumah $28.8 \mathrm{~m}^{2}$ ) & \\
\hline & Pilihan 1 & 27.07 \\
\hline & Pilihan 2 & 27.53 \\
\hline & Pilihan 3 & 19.07 \\
\hline \multirow[t]{4}{*}{2} & Tipe Sedang (luas rumah $36 \mathrm{~m}^{2}$ ) & \\
\hline & Pilihan 1 & 17.55 \\
\hline & Pilihan 2 & 21.93 \\
\hline & Pilihan 3 & 20.24 \\
\hline \multirow[t]{4}{*}{3} & Tipe Besar (luas rumah $43.2 \mathrm{~m} 2$ ) & \\
\hline & Pilihan 1 & 16.24 \\
\hline & Pilihan 2 & 13.95 \\
\hline & Pilihan 3 & 8.59 \\
\hline
\end{tabular}

Dari hasil perhitungan luas area ruang terbuka hijau didapat bahwa konfigurasi massa yang melebar (pilihan 2) memiliki luas ruang terbuka hijau yang besar khususnya pada tipe kecil dan tipe sedang, sedangkan pada tipe besar luas ruang terbuka hijau yang paling besar adalah pada konfigurasi massa memanjang (pilihan 1). Hal ini berdampak kemungkinan aliran udara dan cahaya alami akan menjadi lancar sehingga membuat ruang dalam rumah menjadi nyaman.

Setelah melakukan eksplorasi desain layout denah rumah dalam beberapa alternatif, dilakukan tahap akhir yaitu eksplorasi desain modul struktur sesuai dengan denah yang telah dibuat. Eksplorasi desain modul struktur hanya dilakukan pada kasus tipe kecil dengan ukuran modul paling kecil adalah $2.4 \mathrm{~m}$. Hal ini dimaksudkan untuk melihat kemungkinan desain struktur diaplikasikan pada ukuran terkecil. Jenis struktur yang dikembangkan adalah berdasarkan material khususnya material rumah prefab yang telah dikembangkan sebelumnya yaitu menggunakan material beton RISHA, baja, baja ringan, dan kayu. Dari hasil eksplorasi desain struktur rumah prefabrikasi yang dilakukan, jenis struktur beton panel RISHA dianggap tidak cocok untuk membuat ukuran ruangan dengan modul terkecil 2.4 x 2.4 m karena telah memiliki standar modul ukuran panel sendiri. Jika menggunakan panel RISHA sebagai komponen struktur utama, maka akan didapat ukuran ruangan minimal adalah 3 x $3 \mathrm{~m}$. Untuk jenis material yang lainnya (baja, baja ringan, dan kayu), dapat menyesuaikan ukuran minimal 2.4 x $2.4 \mathrm{~m}$. Berikut ini adalah hasil eksplorasi desain struktur pada rumah khususnya pada tipe kecil yang dijadikan sebagai studi kasus: 


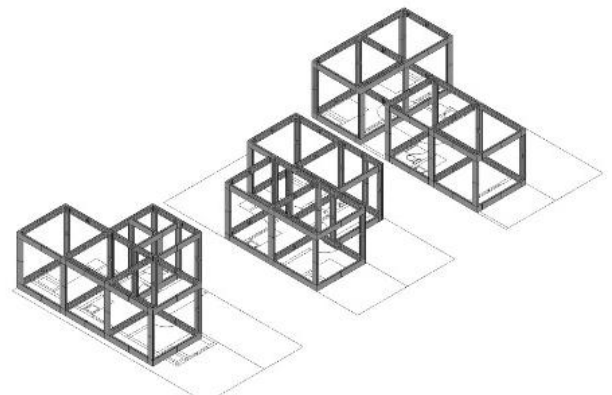

Eksplorasi desain struktur menggunakan panel beton RISHA

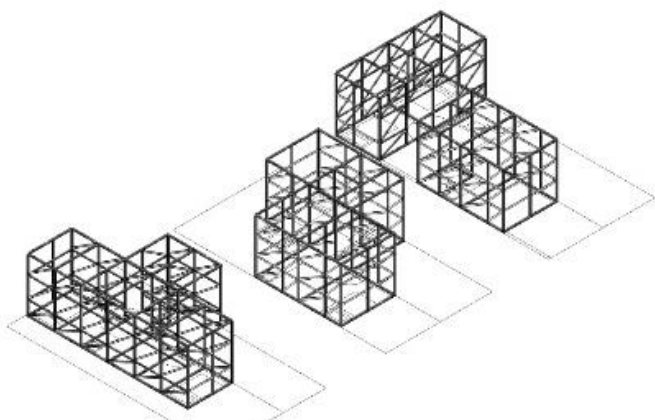

Eksplorasi desain struktur menggunakan struktur baja ringan

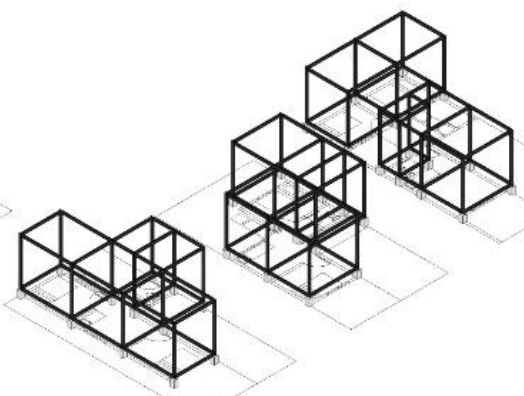

Eksplorasi desain struktur menggunakan struktur baja dengan pondasi setempat atau umpak

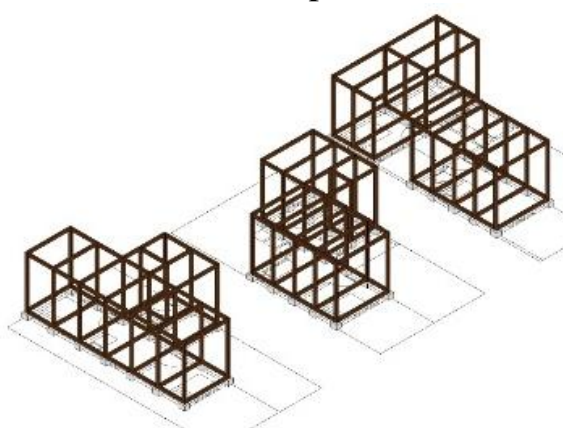

Eksplorasi Desain Struktur menggunakan struktur kayu

Gambar 2. Eksplorasi desain struktur pada alternatif tipe kecil

\section{KESIMPULAN}

Desain rumah prafabrikasi dapat memiliki bentuk yang bermacam-macam dan dapat menghilangkan kesan monotonnya dengan merancang modul strukturnya terlebih dahulu. Bentuk modul akan mempengaruhi bentuk bangunan dan proporsinya. Selain itu, komposisi modul tertentu juga akan mempengaruhi ukuran luas area taman sehingga akan membuat rumah menjadi terasa semakin nyaman. Dari segi efisiensi penggunaan lahan, bentuk modul yang melebar adalah bentuk massa yang paling efisien karena masih menyisakan ruang terbuka hijau yang besar jika dibandingkan dengan modul bentuk memanjang. Material struktur juga mempengaruhi ukuran modul ruangan yang akan dibuat. Ukuran modul ruangan minimal dengan ukuran 2.4 × $2.4 \mathrm{~m}$ dapat diterapkan pada struktur dengan material kayu, baja, dan baja ringan. Sedangkan, pada struktur beton panel RISHA, ukuran minimal yang dapat diterapkan adalah ukuran $3 \times 3 \mathrm{~m}$. Dari segi durabilitasnya, material struktur baja adalah yang direkomendasikan untuk digunakan sebagai alternatif struktur rumah prafabrikasi bagi rumah tinggal sederhana. 
Ukuran Modul dengan kelipatan $30 \mathrm{~cm}$ dapat beradaptasi dengan berbagai macam material penutup dinding dan lantai yang kebanyakan juga memiliki ukuran dengan kelipatan $30 \mathrm{~cm}$. Sehingga dapat dikatakan sistem modul rumah prafabrikasi dibuat dengan sistem terbuka (open-system). Rumah prafabrikasi dengan sistem terbuka merupakan sistem yang baik karena memungkinkan adanya berbagai macam variasi desain dan aplikasi sehingga diharapkan masyarakat dapat mengembangkan sendiri desain yang diinginkan serta nantinya akan menjadi alternatif bagi rumah sederhana. Selain itu, diperlukan penelitian lebih lanjut tentang pembuatan prototipe rumah prafabrikasi dengan desain yang telah dieksplorasi agar hasil penelitian akan semakin tepat guna bagi masyarakat luas.

\section{UCAPAN TERIMA KASIH}

Penulis mengucapkan terima kasih sebesar-besarnya kepada seluruh pihak yang telah membantu dalam penyusunan penelitian ini. Tak lupa pula disampaikan terima kasih yang sebesar-besarnya kepada mitra bebestari Journal of Applied Science yang telah menerbitkan tulisan penulis ke dalam jurnal ini.

\section{DAFTAR PUSTAKA}

1) SUSESNAS 2011. Survey Sosial Ekonomi Nasional. Badan Pusat Statistik.

2) Smith, Ryan. E. (2010). Prefab Architecture: A Guide to Modular Design and Construction. John Willey and Son. Inc.

3) Amalia, Anggie. (2008). Prafabrikasi, antara Arsitektur, Teknologi, dan Sosial Ekonomi. Skripsi. Teknik Arsitektur Fakultas Teknik Universitas Indonesia.

4) Heston, Yudha Pracastino. (2015). Pengembangan Rumah RISHA dengan Teknologi Knock-Down Sesuai Kebutuhan Kontekstual Lokal. Seminar Nasional SCAN 2015.

5) Primasetra, Anjar. (2015). Studi Industri Konstruksi Rumah Prapabrikasi Lokal Berbasis Komunitas, Kasus: Komunitas Kampung Naga, Tasikmalaya, Jawa Barat. Tesis. Institut Teknologi Bandung.

6) Keputusan Menteri Kipraswil. (2002). "Keputusan Menteri Kimpraswil Nomor 403/KPTS/2002 tentang Rumah Sederhana Sehat."

7) Neufert, Ernst. (1996). Data Arsitek Jilid 1. Jakarta: Erlangga.

8) Suryo,Mahatma Sindu. (2017). Analisa Kebutuhan Luas Minimal Pada Rumah Sederhana Tapak Di Indonesia. Jurnal Permukiman Vol. 12 No. 2 November 2017: $116-123$.

9) SNI 03-1733-2004. Standar Nasional Indonesia Tentang Tata Cara Perencanaan Lingkungan Perumahan di Perkotaan.

10) www.dubldom.ru 